\title{
A educação de hoje rumo à educação planetáría de amanhã
}

\author{
Lucilene Cury \\ Professora associada do Departamento de Comunicações e Artes da Escola de Comunicações \\ e Artes (ECA) da Universidade de São Paulo (USP). \\ E-mail: lucilene@usp.br \\ Marciel Consani \\ Docente e pesquisador do Departamento de Comunicações e Artes da Escola de Comunicações \\ e Artes (ECA) da Universidade de São Paulo (USP). \\ E-mail: marcielc@gmail.com
}

Resumo: Este artigo propõe o início de uma
discussão ampla e aberta sobre as questões que
afetam a educação hoje por conta dos impactos
das mídias digitais num contexto de permanente
conexão com o processo de ensino-aprendizagem.
A premissa básica é que as demandas e os
desafios da educação a distância (EaD) são, em
princípio, os mesmos que afetam a educação
como um todo, ambas profundamente impactadas
pelo paradigma da complexidade em dimensão
planetária - conceitos iluminadores abordados
na obra de Edgar Morin. Ao final desta série de
reflexões, almeja-se pontuar a necessidade de
um olhar que transcenda as questões puramente
tecnológicas e operacionais, ao mesmo tempo
que reafirme a importância e a pertinência da
abordagem educomunicativa.

Palavras-chave: educação; educação a distância; mídias digitais; formação de educadores; educomunicação.
Abstract: This article sets the beginning of a broad and open discussion about the issues affecting education today concerning the impacts of digital media in a context of permanent connection with the teaching-learning process. The basic premise is that the demands and challenges of Distance Education (DE) are, in principle, the same as those that affect education as a whole, both profoundly affected by the complexity paradigm of planetary dimension - illuminating concepts approached in Edgar Morin's work. At the end of this series of reflections, we aim to highlight the need for an outlook that transcends purely technological and operational issues, while reaffirming the importance and pertinence of the educommunicative approach.

Keywords: education; distance education; digital media; educator training; educommunication. 


\section{INTRODUÇÃO}

A partir da ideia básica de que a educação a distância (EaD) não se diferencia da educação em geral, isto é, de suas demandas e desafios, apresentam-se neste artigo algumas considerações sobre as possibilidades que a EaD oferece para o desenvolvimento de um processo educacional realmente efetivo.

As mídias digitais, por sua vez, constituem um capítulo à parte, já que alteram completamente o que era praticado em termos de recursos comunicacionais para a educação. Ao mesmo tempo que o desenvolvimento das tecnologias digitais cresce em ritmo vertiginoso, o mesmo não se pode afirmar sobre seu uso na educação em geral, o que demanda a proposição de políticas públicas capazes defender suas possibilidades em favor de uma educação de qualidade e inclusiva para os que nela precisam estar inseridos.

É preciso assinalar aqui que os autores compartilham, sobre essas questões, o olhar educomunicativo, isto é, alinhado com os pressupostos da educomunicação conforme ressignificados por Soares ${ }^{1}$. Assim, apresentam-se duas abordagens iniciais: (1) a necessidade de inclusão e de acesso a uma educação de qualidade; e (2) a educação e a EaD como diferentes instâncias de um mesmo processo. Na sequência, dá-se o recorte sobre as mídias digitais e as demandas relacionadas com a formação de alunos e professores, que apontam novos caminhos, ao mesmo tempo que trazem novas questões e incertezas. Na seção de número 5 enfatiza-se o caráter "planetário" da educação, tal como vislumbrado neste momento histórico. Por fim, algumas considerações indicam possíveis rumos futuros para os quais esta discussão possa se encaminhar.

\section{EDUCAR EM UM MUNDO QUE SE TRANSFORMA}

O pensamento complexo de Edgar Morin² enfatiza que a educação deve estar inserida no que o autor denominou de era planetária, com um duplo desafio educar "em" e "para" a era planetária - que deve considerar a complexa situação do mundo para além da concepção tecnoeconômica, que parece ignorar os problemas humanos relacionados à identidade, comunidade, solidariedade e cultura.

Para prosseguir com a proposta de tratar a questão da $\mathrm{EaD}$ como uma forma de educação circunscrita em contexto muito mais amplo, como o da era planetária apresentada por Morin, Curana e Motta ${ }^{3}$, busca-se o trabalho do sociólogo José Joaquim Brunner ${ }^{4}$, ex-ministro geral de governo no Chile, que afirma:

Los valores humanos difieren entre las civilizaciones y cambian con la evolución de las sociedades. Dependen de la trayectoria cultural de los pueblos, de las bases éticas y religiosas de cada comunidad, de sus instituciones y costumbres, de la organización del trabajo y los medios de Comunicación, de las maneras de conocer y las formas de vivir.
1. SOARES, Ismar de Oliveira. Educomunicação: o conceito, o profissional, a aplicação: contribuições para a reforma do ensino médio. São Paulo: Paulinas, 2011.

2. MORIN, Edgar. Introdução ao pensamento complexo. Porto Alegre: Sulina, 2007.

3. MORIN, Edgar: CURANA Emilio-Roger; MOTTA, Raúl Domingo. Educar na era planetária: o pensamento complexo como Método de aprendizagem no erro e na incerteza humana. São Paulo: Cortez, 2003.

4. BRUNNER, José Joaquim. Los valores se modernizam o permanecen inmutables? Revista Universum, Talca, n. 13, p. 21-32, 1998. p. 21. 
Dessa forma, quanto à sociedade em rede dos dias atuais, o sociólogo Manuel Castells ${ }^{5}$, já no título de sua obra seminal, propõe o conhecimento desenvolvido pela internet, que altera substancialmente a forma como a informação circula entre todos, de modo que a tecnologia assume papel de destaque no mundo e nas instituições em geral, com especial destaque para as escolas, em todos os seus níveis. Daí, passando pela reconstrução dos saberes e pela ação dos educadores, essa escola assume um papel importante na forma como educa seus alunos, em permanente negociação com outras instâncias educadoras, principalmente a família e a chamada "mídia", isto é, o conjunto dos meios de comunicação - incluindo a internet.

Assim, a educação vem se transformando em consequência do desenvolvimento tecnológico no processo de ensino-aprendizagem, apesar de isso não ocorrer de forma totalmente regular e sistematizada, uma vez que o processo ora deixa de assumir esse papel, ora exacerba no valor atribuído aos suportes tecnológicos em detrimento do que espera poder apresentar em termos de conteúdo, valores e demais aspectos essenciais inerentes ao desenvolvimento do processo educativo, nos seus diversos graus e modalidades.

Insere-se nesse debate, então, a $\mathrm{EaD}$, no âmbito do processo educativo em geral, com as mesmas questões relativas à educação em sentido amplo. As especificidades começam a ser vislumbradas nos aspectos que tratam da presença dos participantes, das mediações realizadas e do tempo dedicado ao estudo, que são elementos responsáveis pelas principais diferenças encontradas entre elas.

\section{REDIMENSIONANDO A DISTÂNCIA NA EDUCAÇÃO}

Se, em um passado não muito distante, era notória a diferença entre a EaD e os processos pedagógicos usuais - entendidos como aqueles baseados na presença concomitante de professores e alunos no tempo e espaço escolar -, o mesmo não se aplica de forma tão clara na atualidade. Exemplo disso, além do mix variável entre atividades síncronas e assíncronas oferecidas nas escolas - o chamado blended learning -, é a natureza permanentemente conectada das interações entre alunos e professores, não só no contexto da aula propriamente dita, mas também na relação didática que os mantém em contato, mesmo longe da escola.

Alguns autores até recusam o qualificativo "a distância" para denominar essa abordagem didática, que preferem denominar "virtual" ou "on-line" - como Romero Tori quando aponta que "educação a distância" é "uma expressão que dá destaque ao problema, e não à solução" (sendo a distância justamente o obstáculo que se quer eliminar).

A "distância" não é mais a grande diferença, uma vez que já não pode ser considerada como era antes, principalmente a partir da década de 1970, quando se expandem grandes projetos de $\mathrm{EaD}$ no Brasil. Estados como os da região amazônica brasileira, dentre outros, por suas grandes extensões e pela 
dificuldade de acesso às vantagens de transporte e locomoção existentes nas demais regiões do país, devida a rios, florestas e demais circunstâncias geográficas e/ou socioeconômicas, foram responsáveis pelos melhores programas de EaD desenvolvidos nesses tempos, muito provavelmente porque a necessidade foi motor propulsor de desenvolvimento dessa modalidade de educação no Brasil.

Hoje, além de não ser mais entendida como fator determinante, a ideia de distância não é mais a mesma, inclusive pela amplitude das chamadas cidades globais, conectadas entre si pelos recursos tecnológicos à disposição de grande parte das populações, o que permitiu a Litto afirmar que com a vigência do "mobile learning é possível aprender em qualquer momento e em qualquer lugar" ", levando à utilização da metodologia de EaD para superar dificuldades de tempo, transporte e outras, inclusive nas grandes metrópoles, com é o caso de São Paulo.

Além disso, com a promulgação da atual Lei de Diretrizes e Bases da Educação Nacional (LDB, ou Lei no $\left.{ }^{0} 9394 / 1996\right)^{8}$, verifica-se a possibilidade de utilizar a $\mathrm{EaD}$ em todos os níveis de educação (desde que o aluno tenha mais de 18 anos). A legislação esclarece ainda que essa modalidade deve ser incentivada com tratamento diferenciado no que diz respeito aos meios de comunicação. Um bom exemplo da lei é a existência da Portaria no ${ }^{\mathbf{0}}$ 4.059/2004, do Ministério da Educação ${ }^{9}$, que regulamentou aulas semipresenciais de até $20 \%$ dos conteúdos nos cursos reconhecidos das instituições de educação superior, independentemente de credenciamento pela unidade.

Portanto, passados mais de vinte anos da promulgação da LDB, pode-se verificar que muitas das questões tratadas à época (no ano de 1996), como a chamada educação de segunda classe, por exemplo, ainda podem ser citadas. Hoje, porém, elas têm muito menos importância, uma vez que os meios de comunicação multiplicaram-se de maneira exponencial e a denominada "sociedade da informação" traz no seu bojo o uso cada vez mais acentuado dessas ferramentas, imprescindíveis para o desenvolvimento da $\mathrm{EaD}$ e da educação em geral.

Igualmente, propõe-se a necessidade de sintonizar a comunicação e a educação, não somente com o uso de materiais de trabalho, mas também para divulgação e socialização do que se realiza em termos de conteúdos e metodologia, o que nos obriga a tratar da abordagem midiática.

\section{A QUESTÃO DAS MÍDIAS DIGITAIS NA FORMAÇÃO DE ESTUDANTES E EDUCADORES}

As mídias digitais constituem um capítulo à parte, já que alteraram completamente o que usualmente se praticava em termos de recursos comunicacionais para a educação. Ao passo que o desenvolvimento das tecnologias digitais cresce em ritmo vertiginoso, não se pode afirmar o mesmo sobre seu uso na educação em geral. Muitos são os exemplos de trabalhos educacionais bem-sucedidos, mas
7. LITTO, Fredric Michael: FORMIGA, Manuel Marcos Maciel (org.). Educação a distância: o estado da arte. São Paulo: Pearson Education do Brasil, 2009. p. 19.

8. BRASIL. Ministério da Educação. Lei n 9.394, de 20 de dezembro de 1996 Estabelece as diretrizes e bases da Educação Nacional. Diário Oficial da União, Brasília, DF, p. 27833, 23 dez. 1996. Disponível em: http://www.planalto.gov. br/ccivil_03/leis//9394.htm. Acesso em: 30 dez. 2019.

9. BRASIL. Ministério da Educação. Portaria n 4.059, de 10 de dezembro de 2004. Diário Oficial da União: seção 1, Brasília, DF, p. 34, 13 dez. 2004. Disponível em: http://portal.mec. gov.br/sesu/arquivos/pdf/ nova/acs_portaria4059.pdf. Acesso em: 15 nov. 2019. 
10. ORGANIZACÃO DAS NAÇÕES UNIDASS PARA A EDUCACÃO, A CIÊNCIA E ACULTURA. Alfabetização midiática e informacional: diretrizes para a formulação de políticas e estratégias: resumo sobre as políticas da AMI. Brasília, DF: Unesco, 2016.

11. NISKIER, Arnaldo. Os aspectos culturais e a EAD. In: LITTO, Fredric Michael; FORMIGA, Manuel Marcos Maciel (org.). Educação a distância: o estado da arte. São Paulo: Pearson Education do Brasil. p. 30

12. CASTELLS, Manuel. Ruptura: a crise da democracia liberal. Rio de Janeiro: Zahar, 2018. p. 149 em uma proporção muito menor que o atual desenvolvimento tecnológico, em parte por falta de recursos econômicos, de gestão e de políticas públicas, mas também, e principalmente, por falta de interesse de muitos - incluindo gestores, educadores e até estudantes - em acompanhar essa mudança irreversível dos tempos globais, de grande velocidade e espaço desterritorializado.

Nessa linha de pensamento sobre os recursos imprescindíveis para a educação na era digital, em crescente ampliação e desenvolvimento, a Organização das Nações Unidas para a Educação, a Ciência e a Cultura (Unesco) propõe diretrizes importantes no que diz respeito à formulação de estratégias de políticas públicas para a educação formal e não formal, a fim de que seja possível obter os seguintes benefícios: (1) maior participação ativa e democrática; (2) maior conscientização sobre as responsabilidades éticas da cidadania global; (3) atenção à diversidade; (4) abertura para o diálogo; e (5) promoção da tolerância ${ }^{10}$.

$\mathrm{Na}$ educação, tanto na abordagem presencial quanto na $\mathrm{EaD}$, os principais benefícios para uma mudança necessária incluiriam: (1) o uso das mídias digitais num contexto de alfabetização midiática e informacional, favorecendo a criação de uma ponte entre a sala de aula física e o ambiente digital; (2) o alcance da formação dos profissionais da educação, por meio de estratégias e recursos on-line, ampliando seu repertório didático-pedagógico e atribuindo-lhes um papel ativo no que se denomina de educação continuada; e (3) a formação de estudantes e professores para/pelas mídias digitais, garantindo uma participação maior e mais plena na vida econômica, política e social para atingir o desenvolvimento de uma cidadania ativa (inclusão digital).

Ao pensarmos em competência - de alunos, professores e especialistas em $\mathrm{EaD}$-, surge a seguinte questão, ainda que de modo latente: o que significa essa competência? Para Niskier ${ }^{11}$, a formação de educadores perpassa a dimensão técnica, a dimensão humana, o contexto político-econômico e a parte dos conhecimentos a serem transmitidos, sendo tudo isso resumido no que se pode chamar de aquisição de competências, que abrange, necessariamente, o saber e o fazer, a teoria e a prática, e os princípios e processos da tecnologia educacional.

Dessa forma, ainda que não seja o ápice do tripé comunicação/educação/ tecnologia digital - em termos de importância no processo de ensino-aprendizagem -, a tecnologia é uma necessidade para o desenvolvimento da educação nestes novos tempos. Como afirma Castells ${ }^{12}$, "cada um é produto de sua época”, o que permite refletir sobre as possibilidades que o professor tem de entregar material educativo e conteúdo científico por plataformas eletrônicas, cada vez mais especializadas, que demandam conhecimento técnico por parte de quem delas se utiliza.

Surgem, portanto, profissionais responsáveis pela adequação do conteúdo às novas formas de apresentação do material e de entrega ao sujeito receptor, que pode estar presente ou distante. Partindo dessa reflexão, emergem várias questões:

1) O professor precisa ser educado para o trabalho docente circunscrito nesse novo cenário pedagógico? 
2) As tarefas do professor serão diversificadas entre gerador e organizador de conteúdo nas plataformas digitais/eletrônicas?

3) O tutor tem desempenho diferenciado para prestar auxílio aos alunos?

4) $\mathrm{O}$ aluno precisa necessariamente ter sido alfabetizado do ponto de vista informático?

5) As dificuldades encontradas podem ser mais de caráter técnico do que de entendimento do assunto?

6) Há possibilidade de que o ensino a distância não esteja voltado para as necessidades cognitivas do sujeito receptor?

7) A distância entre os atores do processo de ensino-aprendizagem pode ser facilmente superada pelo universo on-line propiciado pela internet?

Tais perguntas - e várias outras que podem ser acrescentadas - dirigem-se às ideias acima apresentadas, tais como a educação presencial e virtual, simultaneamente; a formação de professores para os tempos atuais e os que virão, cada vez mais rápidos e desenfreados; os sistemas de ensino particular e público; o nível dos alunos em termos de escolaridade; a qualidade dos suportes tecnológicos das escolas e das residências, além do acesso proporcionado, principalmente, pelas políticas públicas de educação.

\section{DE VOLTA À ERA PLANETÁRIA}

Com o objetivo de inserir as possibilidades da EaD no contexto da educação em geral, comparando sua situação nos diversos países deste mundo globalizado e com alta interconexão entre seus habitantes, são usadas as proposições sugeridas por Morin (Figura 1), Curana e Motta ${ }^{13}$. Explicam eles, no livro Educar na era planetária, que o termo "planetarização" é mais complexo que "globalização" (nome quase sempre usado para descrever unicamente a mundialização das dimensões econômica e tecnológica) por ser uma expressão radicalmente antropológica, que engloba o planeta Terra em sua totalidade complexa: física, biológica e antropológica. "Em outras palavras, é preciso compreender a vida como consequência da história da Terra e a humanidade como consequência da história da vida na terra" ${ }^{14}$.

Assim, a conscientização a respeito dessa necessidade de tratar a educação no contexto da era planetária leva a um duplo desafio: o de educar "em" e "para" essa era, considerando a complexa situação do mundo, para além da concepção tecnoeconômica, que ignora os problemas humanos da identidade, da comunidade, da solidariedade e da cultura.

É preciso, portanto, dar um salto na "ideologia" do progresso como motor suficiente para todos os desenvolvimentos sociais, psíquicos e morais - coisa que ele não é. De mãos dadas com essa ideologia do progresso encontram-se as tecnologias e as mídias digitais, o que nos interessa tratar no âmbito da educação, em seus diferentes espaços para além da escola, com a finalidade

13. MORIN; CURANA; MOTTA, op. cit.

14. Ibidem, p. 63 
15. Disponível em: https:// commons.wikimedia. org/w/index.php?curid $=55840215$. Acesso em: 30 dez. 2019

16. PISANI, Francis; PIOTET, Dominique. Como a web transforma o mundo: a alquimia das multidões. São Paulo: Editora Senac São Paulo, 2010.

17. Ibidem primordial de propiciar uma mundiologia da vida cotidiana (frase inspirada numa expressão do escritor argentino Ernesto Sábato) para tratar da necessidade urgente da sociedade de contar com "mundólogos" que permitam orientar à civilidade na percepção dos problemas mais urgentes e globais.

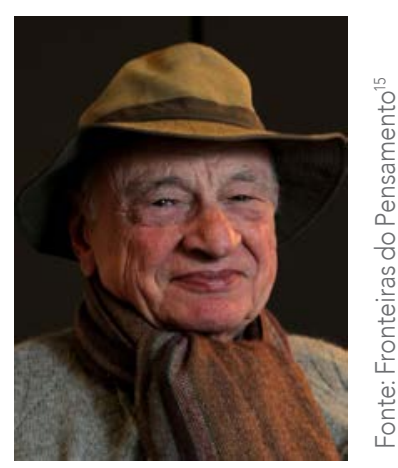

\section{Edgar Morin em foto de 2011}

Assim, seguindo a análise sobre o papel das tecnologias digitais no trabalho educativo de hoje, com a transformação do mundo pela web (conforme sugere o livro Como a web transforma o mundo ${ }^{16}$ ), pode-se vislumbrar a virtualidade de um novo espaço, ainda a ser explorado, capaz de levar à inteligência coletiva, característica essencial da sociedade em rede - conectada, interligada, de aspectos colaborativos entre todos e de mutações individuais para a constituição de comportamentos coletivos.

Mais do que tratar do uso das tecnologias digitais, importa pensar como elas estão alterando o mundo e até onde podem chegar. Os autores de Como a web transforma o mundo, Francis Pisani e Dominique Piotet ${ }^{17}$, juntamente com Antoine Sire ${ }^{18}$, que escreve o posfácio, abordam essa questão de forma bastante interessante. As principais proposições da obra são:

1) a web como espaço social da adolescência - a ferramenta social e o espaço em que as relações ocorrem;

2) a tecnologia pouco importa e desaparece em benefício da utilização que se faz dela;

3) o que os jovens amam são as redes de relacionamento, que encontram na internet uma ferramenta poderosa de socialização;

4) a falta de mobilidade e de acesso a um espaço real e físico para os jovens, onde possam estar juntos sem ser interrompidos e observados, leva à transformação dos sites em espaços públicos, ainda que virtuais;

5) a web serve para estabelecer elos entre as pessoas (é sua dimensão mais popular);

6) as redes são a nova geometria do mundo moderno, e compreendê-las tornou-se a disciplina equivalente à cartografia há alguns séculos;

7) a dinâmica da "linkagem" se evidencia numa metáfora segundo a qual as redes apresentam a arquitetura da complexidade, de forma que as mensagens 
circulam ao longo dos links da internet como as reações químicas que acontecem, de modo similar, nas conexões entre células;

8) a era da web é uma era conectada, na qual o número de pessoas conectadas e sua forma de conexão mudam constantemente, conforme mudam os aspectos tecnológicos e econômicos;

9) cada conexão diz algo sobre o que está conectado, sobre aquele que estabeleceu a conexão e sobre a cultura em que este está inserido;

10) os especialistas não são mais os mesmos de antes: eles não desaparecem, mas assistimos a uma espécie de negociação social do conhecimento;

11) o conhecimento tornou-se um conhecimento social, e os estudantes estão on-line quando fazem as lições de casa, assim como quando estão na escola.

Por fim, conforme formula Antoine Sire ${ }^{19}$, o grande desafio parece ser: como apostar numa "inteligência social coletiva" sem a modulação direta dos poderes constituintes da sociedade como é conhecida? Esse desafio está diretamente ligado a quem se dedica à educação, seja na modalidade presencial, virtual ou presencial e virtual, tal como conceituado desde o início deste trabalho.

Educar-se "para" e "na" era planetária consiste em considerar o homem em toda sua complexidade, circunscrito no planeta Terra e, portanto, em comunicação com todos os demais seres vivos da natureza. Isso inclui as crianças e os jovens, independentemente de serem considerados "nativos digitais" - já que o termo é bastante polêmico -, pois estes já vivem na era da web, de conexões entre todos e entre informações e pessoas.

\section{CONSIDERAÇÕES FINAIS}

Como ficamos nós, os educadores, diante do desafio de educar hoje? Primeiro, é preciso deter o conhecimento que dá legitimidade para participar do processo de educação, devendo-se passar pelas disciplinas, de modo inter ou transdisciplinar, sem, no entanto, que se abra mão do saber próprio de cada especialidade. Por outro lado, é preciso conhecer os participantes desse processo educativo: saber quem são os alunos, com toda sua complexidade, seja do ponto de vista intelectual, cultural ou outros. Essa ação pedagógica precisa ser realizada por meio da ética da compreensão, conforme proposto por Edgar Morin ${ }^{20}$, o que equivale à necessidade de afeto, em sua forma mais ampla.

Quanto às mídias digitais, atualmente em estágio muito desenvolvido no que diz respeito ao mundo on-line, é necessário utilizá-las em todas as suas possibilidades e nuances, sem, porém, colocá-las em primeiro plano, pois esse não é o seu lugar. Antes disso, há toda uma teia de relações humanas, de conteúdos produzidos sistematicamente pelas ciências ao longo dos séculos, de necessidades intelectuais e de demais habilidades cognitivas dos educandos a serem desenvolvidas pelos educadores.

Cabe finalizar afirmando que essa problemática e seus desdobramentos estão no centro das discussões na maior parte dos centros de formação de
18. SIRE, Antoine. Posfácio In: PISANI, Francis; PIOTET Dominique. Como a web transforma o mundo: a alquimia das multidões. São Paulo: Editora Senac São Paulo, 2010. p. 301-304.

19. Ibidem.
20. MORIN, Edgar. Os sete saberes necessário a educação do futuro. São Paulo: Cortez; Brasília, DF: Unesco, 2003.

21. Disponível em: https:// www5.usp.br/ensino/graduacao/cursos-oferecidos/ educomunicacao/. Acesso em: 30 dez. 2019. 
comunicação \& educação • Ano XXIV • número 2 • jul/dez 2019

educadores - incluindo o curso de licenciatura em Educomunicação da Escola de Comunicações e Artes (ECA) da Universidade de São Paulo (USP) ${ }^{21}$. Tais profissionais, hoje, são importantes para desempenhar o papel de mediação entre o mundo, com todas as suas possibilidades e dificuldades, e os alunos os verdadeiros sujeitos do processo educativo.

\section{REFERÊNCIAS BIBLIOGRÁFICAS}

BRASIL. Ministério da Educação. Lei no 9.394, de 20 de dezembro de 1996. Estabelece as diretrizes e bases da Educação Nacional. Diário Oficial da União, Brasília, DF, p. 27833, 23 dez. 1996. Disponível em: http:/ /www.planalto.gov.br/ ccivil_03/leis/19394.htm. Acesso em: 30 dez. 2019.

BRASIL. Ministério da Educação. Portaria nº 4.059, de 10 de dezembro de 2004. Diário Oficial da União: seção 1, Brasília, DF, p. 34, 13 dez. 2004. Disponível em: http://portal.mec.gov.br/sesu/arquivos/pdf/nova/acs_portaria4059.pdf. Acesso em: 15 nov. 2019.

BRUNNER, José Joaquim. Los valores se modernizam o permanecen inmutables? Revista Universum, Talca, n. 13, p. 21-32, 1998.

CASTELLS, Manuel. A sociedade em rede. São Paulo: Zahar, 2009.

CASTELLS, Manuel. Ruptura: a crise da democracia liberal. Rio de Janeiro: Zahar, 2018.

LITTO, Fredric Michael; FORMIGA, Manuel Marcos Maciel (org.). Educação a distância: o estado da arte. São Paulo: Pearson Education do Brasil, 2009.

MORIN, Edgar. Os sete saberes necessário a educação do futuro. São Paulo: Cortez; Brasília, DF: Unesco, 2003.

MORIN, Edgar. Introdução ao pensamento complexo. Porto Alegre: Sulina, 2007. MORIN, Edgar; CURANA, Emilio-Roger; MOTTA, Raúl Domingo. Educar na era planetária: o pensamento complexo como Método de aprendizagem no erro e na incerteza humana. São Paulo: Cortez, 2003.

NISKIER, Arnaldo. Os aspectos culturais e a EAD. In: LITTO, Fredric Michael; FORMIGA, Manuel Marcos Maciel (org.). Educação a distância: o estado da arte. São Paulo: Pearson Education do Brasil, 2009. p. 28-33.

ORGANIZAÇÃO DAS NAÇÕES UNIDAS PARA A EDUCAÇÃO, A CIÊNCIA E A CULTURA. Alfabetização midiática e informacional: diretrizes para a formulação de políticas e estratégias: resumo sobre as políticas da AMI. Brasília, DF: Unesco, 2016.

PISANI, Francis; PIOTET, Dominique. Como a web transforma o mundo: a alquimia das multidões. São Paulo: Editora Senac São Paulo, 2010. 
SIRE, Antoine. Posfácio. In: PISANI, Francis; PIOTET, Dominique. Como a web transforma o mundo: a alquimia das multidões. São Paulo: Editora Senac São Paulo, 2010. p. 301-304.

SOARES, Ismar de Oliveira. Educomunicação: o conceito, o profissional, a aplicação: contribuições para a reforma do ensino médio. São Paulo: Paulinas, 2011.

TORI, Romero. Educação sem distância: as tecnologias interativas na redução de distâncias em ensino e aprendizagem. São Paulo: Editora Senac São Paulo, 2010. 